\title{
Alterations in Tissue Structure and Morphology in Apo E-KO Mice: The Impact of Dietary Lipids and Heart Transplantation
}

\section{Moghadasian $\mathbf{M H}^{1,2^{*}}$}

${ }^{1}$ Department of Human Nutritional Sciences and the Canadian Centre for Agri-Food Research in Health and Medicine, St. Boniface Hospital Research Centre and the University of Manitoba, Canada

${ }^{2}$ International Nutrition Research Inc., Winnipeg, Canada

*Corresponding author: Moghadasian MH, International Nutrition Research Inc., 351 Tache Ave Winnipeg, Canada R2H 2A6, Tel: 2042353934; Fax: 2042374018; Email: mmoghadasian@sbrc.ca

Received date: Jan 05, 2016; Accepted date: Jan 23, 2016; Published date: Jan 25, 2016

Copyright: (C) 2016 Moghadasian MH. This is an open-access article distributed under the terms of the Creative Commons Attribution License, which permits unrestricted use, distribution, and reproduction in any medium, provided the original author and source are credited.

\begin{abstract}
In this article, the impact of dietary lipids and heterotopic heart transplant procedures on the structure and morphology of several tissues in apolipoprotein E-knock out (apo E-KO) mice is reported. In particular, addition of dietary cholesterol, plant sterol or either changes in hemodynamic factors or immunological responses after heart transplant procedures are associated with histological and cytological changes in the kidneys, skin, heart and arteries in this animal model. In this report, alterations in the vessel wall structure and morphology including formation of atherosclerotic plaques, infiltration of macrophages, as well as evidence for rejection of the donor hearts and formation of non-specific vacuolation in the liver and kidney have been illustrated. In conclusion, various factors may cause changes in tissue structure and morphology which may lead to tissue dysfunction. Early detection of such changes and appropriate remedies including dietary and lifestyle modifications may help sustain tissue structure and function.
\end{abstract}

Keywords: Dietary lipids; Transplantation; Morphology; Heart; Liver; Kidney; Artery

\section{Introduction}

Intact tissue structure and morphology assure physiologic functions of the organ. Many disorders are developed due to alterations in tissue structure and cellular morphology. These changes could be the results of modifiable or non-modifiable factors. Among non-modifiable factors one may include aging or genetic abnormalities. Many body tissues and organs undergo morphological alterations, leading to organ dysfunction due to aging. One good example could be alterations in the central nervous system morphology which may lead to memory loss in elderly [1]. Another common example is reduced bone density leading to osteoporosis and bone fractures [2]. Genetic abnormalities may also lead to morphological changes and tissue function. For example, people with sickle cell anemia show abnormal structure and morphology in their red blood cells leading to anemia and associated abnormalities [3].

Many modifiable factors including dietary, surgical, immunological and environmental agents are capable of altering certain tissue structure and function. These changes may lead not only to organ dysfunction but also to development of totally different tissue structure with loss of function. Excessive alcohol drinking may lead to cirrhosis with totally undetectable hepatocyte in affected segment of the liver [4]. Excessive cigarette smoking is another example of modifiable factor for a complete change in tissue structure and morphology which in many cases may lead to various pulmonary disorders [5]. Organ rejection after transplantation is another example of changing in tissue structure and morphology leading to complete rejection of the graft [6]. On the other hand, under certain conditions, some dietary agents and/or life style modifications are employed to correct such tissue abnormalities. For example, it is believed that increasing HDLcholesterol concentrations through dietary or life style modifications may remove cholesterol from peripheral tissues through reverse cholesterol transport mechanism [7]. Removing accumulated cholesterol clefts in arterial wall helps with maintain normal vessel function. On the other hand, significantly elevated LDL-cholesterol levels may also be associated with cell dysfunctions and tissue abnormalities.

Over the past couple of decades, our laboratory has studied the impact of the quality and quantity of dietary lipids on tissue structure and morphology in a number of experimental animals, particularly apolipoprotein E-knock out (apo E-KO) and LDL-receptor-knock out (LDL-r-KO) mice and their wild-type counterparts, namely C57BL6 mice. In this article, our observations on alterations in tissue structure and morphology under various experimental conditions in apo E-KO mice are summarized.

\section{Dietary Approaches}

Apo E-KO mice lack the gene for apolipoportein $\mathrm{E}$ and therefore accumulate cholesterol in both circulation (in the form of $\beta$-VLDL) and certain body tissue [8]. Such an increased level of blood cholesterol is believed to play a crucial role in spontaneous atherogenesis in this animal model. This process of atherogenesis can be further accelerated by addition of a small amount of dietary cholesterol to the diets of these animals. We have shown repeatedly that these animals develop skin lesions and abnormal histological features in several internal organs [9]. For example, Figure 1 presents development of apparently cutaneous xanthomatosis in male apo EKO mice fed with a diet enriched with $0.15 \%(w / w)$ dietary cholesterol. Abundant cholesterol clefts forming cholesterol granulomas are visible 
in Panel B; accumulation of other types of lipids is shown through oil red $\mathrm{O}$ staining in Panel $\mathrm{C}$ of this figure.

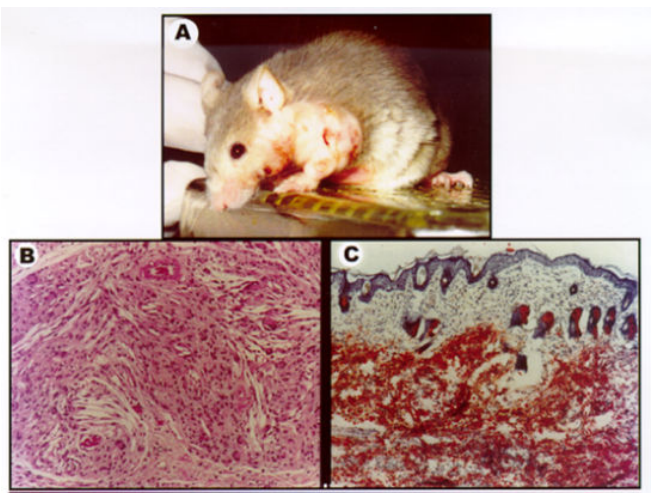

Figure 1: Representative photographs of skins lesions in cholesterolfed apo E-KO mice. Panel A shows eruptive skin lesion on the shoulder area; Panels B and C present photomicrographs of the nuchal skin illustrating marked infiltration by lipids and presence of cholesterol granulomas and cholesterol clefting in Panel B (hematoxylin and eosin stain X50), and prominence of oil red $\mathrm{O}$ staining in Panel C (X25) [9].

In the same experimental model, we also observed non-specific vacuolation in both the liver and kidneys of these animals. Our oil red $\mathrm{O}$ staining procedures failed to stain these apparent vacuoles, therefore, it is speculated that these vacuoles may not be related to lipid deposits. It was interesting to observe that the extent and distribution of such vacuolation were significantly decreased when a phytosterol mixture at $2 \%(\mathrm{w} / \mathrm{w})$ was added to the cholesterol-enriched diet Figures 2 and 3 present such morphological changes and their inhibition by dietary phytosterols in the liver and kidney, respectively, in these animals. It should be mentioned that dietary phytosterols reduce serum cholesterol levels in both animals and humans $[10,11]$.

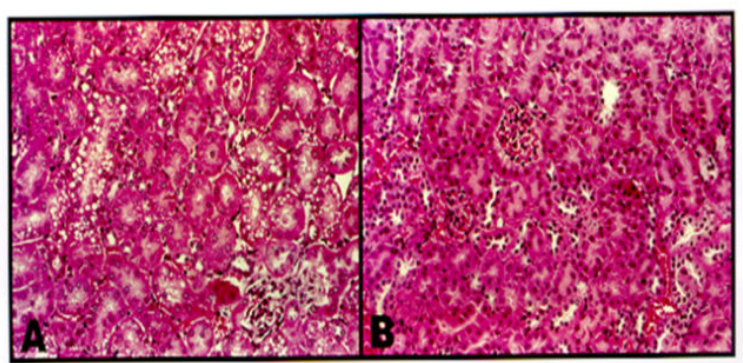

Figure 2: Representative photomicrographs of kidneys from cholesterol-fed (Panel A) and one cholesterol+phytosterol-fed (Panel B) apo E-KO mice. As is evident, vaculation is predominantly seen in Panel A. Hematoxylin and eosin stain, A and $\mathrm{B}, \mathrm{X} 40$ [9].

Vascular tissues are predominantly affected by the lack of apo E gene and dietary cholesterol feeding in this animal model. Wild-type mice do not develop spontaneous or cholesterol-induced atherosclerosis [12]. However, spontaneous atherosclerotic lesion development has been widely reported in apo E-KO mice.

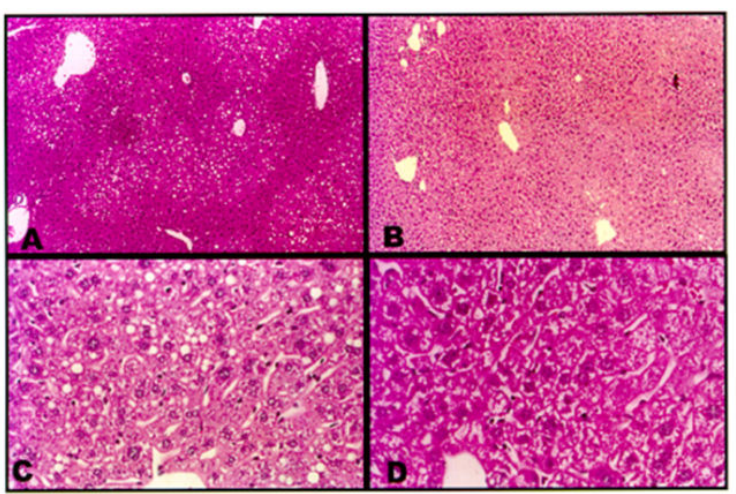

Figure 3: Representative photomicrographs of livers from cholesterol-fed (Panels A and C) and one cholesterol+phytosterolfed (Panels B and D) apo E-KO mice. As is evident, non-specific vacuolation is predominantly seen in Panels A and D. Hematoxylin and eosin stain, A and B, X16; C and D X40 [9].

Dietary cholesterol significantly accelerates this process, leading to fully developed complex atherosclerotic lesions in both aortic roots and the aorta of these animals. We showed that formation of atherosclerotic lesions in the aortic roots can be significantly prevented by dietary phytosterols [13]. The main mechanism for such effective therapy would be a reduction in serum cholesterol levels by phytosterols. However, when we treated these animals with probucol-a strong cholesterol lowering agent with antioxidant properties- to our surprise the formation and complexity of atherosclerotic lesions were significantly deteriorated [14]. Such an extensive atherogenesis was associated with many structural and morphological changes in the vessel wall. These changes included rupture of internal and external elastic lamina, aortic aneurysm, accumulation of foam cells, cholesterol clefts and inflammatory cells in the media and complete obstruction of small coronary arteries. Figures 4 and 5 present significant changes in the vessel wall structure and morphology in the aortic roots and thoracic aorta of apo E-KO mice fed with a commercial mouse chow; the extent and severity of such lesions were significantly increased or decreased when $1 \%(\mathrm{w} / \mathrm{w})$ probucol or $2 \%$ (w/w) phytosterol mixture (FCP-3PI), respectively, was added to the diet.

\section{Surgical Approaches}

Apo E-KO mice and 129 mice were used to perform a series of heterotopic heart transplant procedures in the form of syngraft and allograft. The donor heart was grafted in the abdomen of the recipient mouse using standard surgical procedures [15-17]. We observed that the development of atherosclerotic lesions in the aortic roots as well as ascending aorta of the syngraft was significant enhanced. Such observations suggest that accelerated atherosclerotic lesion development in this model is most likely due to changes in hemodynamic factors. Thus, this observation indicates that permanent alterations in hemodynamic factors may lead to alterations in tissue structure and morphology. Our observation is presented in Figure 6, 
where the oil red O staining show massive lipid deposition in the aortic roots, coronary arteries and ascending aorta of the syngraft.

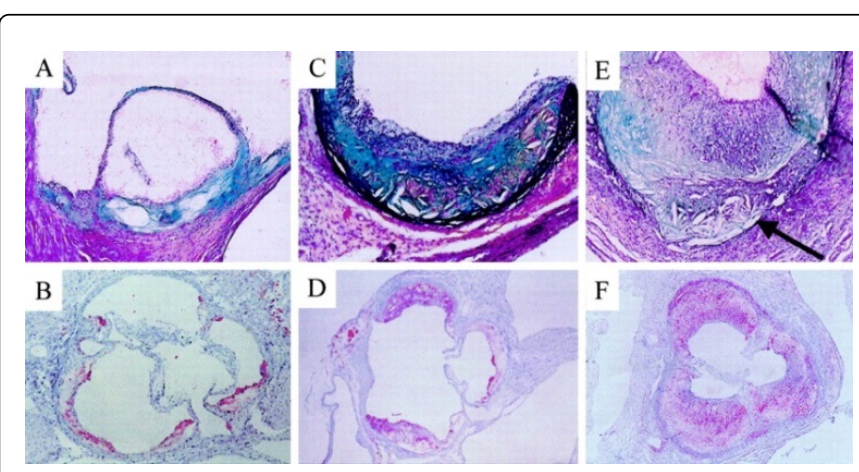

Figure 4: Representative photomicrographs of serial transverse sections at the level of the aortic valve cusps taken from individual mice from FCP-3PI-treated (A and B), control (C and D), and probucol-treated (E and $\mathrm{F}$ ) groups. The volume and complexity of the atherosclerotic lesions are markedly reduced in $\mathrm{A}$ and $\mathrm{B}$ and increased in $\mathrm{E}$ and $\mathrm{F}$, respectively, compared with $\mathrm{C}$ and $\mathrm{D}$. Whereas the ORO stain (B, D, and F) emphasizes lipid accumulation in the lesions, Movat pentachrome stain (A, C, and E) highlights components of the lesions including interstitial matrix, foam cells, and cholesterol clefts. E also illustrates an area of aortic wall destruction with evidence of apparent early aortic aneurysm formation (arrow) (original magnification $\times 25, \mathrm{~B}, \mathrm{D}$, and $\mathrm{F}$; A, C, and $\mathrm{E} \times 50$ ). FCP-3PI was a phytosterol mixture [14].

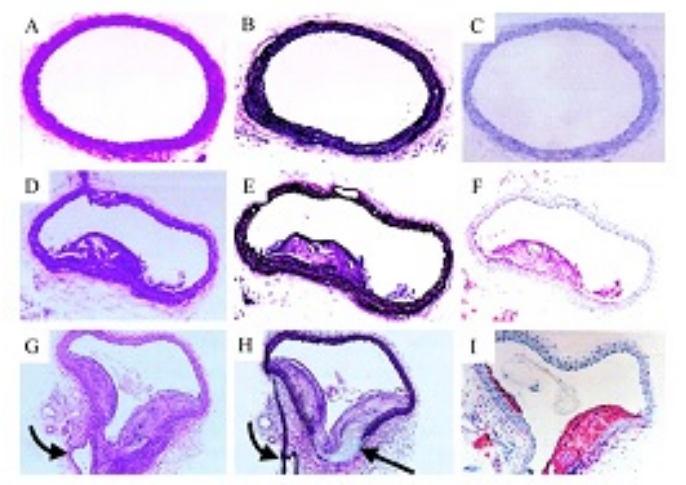

Figure 5: Representative photomicrographs of transverse sections of thoracic aortas from individual mice from FCP-3PI-treated (A, B, and $C)$, control (D, E, and F), and probucol-treated (G, H, and I) groups stained with hematoxylin and eosin (A, D, and $\mathrm{G})$, Movat pentachrome (B, E, and $\mathrm{H})$, and ORO (C, F, and I). Sections from FCP-3PI-treated animals show no visible intimal lesions and normal musculoelastic layers. Sections from both control and probucol-treated mice reveal advanced atherosclerotic lesions containing foam cells, cholesterol clefts, and increased interstitial matrix. As is apparent, the nature of the lesions is more complex in the probucol-treated animal. $\mathrm{H}$ shows complete disruption of media (straight arrow) at a bifurcation point (curved arrow) in the probucol-treated mouse (A through $\mathrm{F}$, original magnification $\times 25$; $\mathrm{G}$ through $\mathrm{I} \times 50)$. FCP-3PI was a phytosterol mixture [14].
When we developed allograft model using apo E-KO mice with C56BL/6 J background and 129J wild-type mice, we noticed myocardium rejection plus early changes in the coronary arteries of the allografts. These observations are presented in Figures 7 and 8, respectively. Main characteristics of the experimental mouse models are summarized in Table 1.

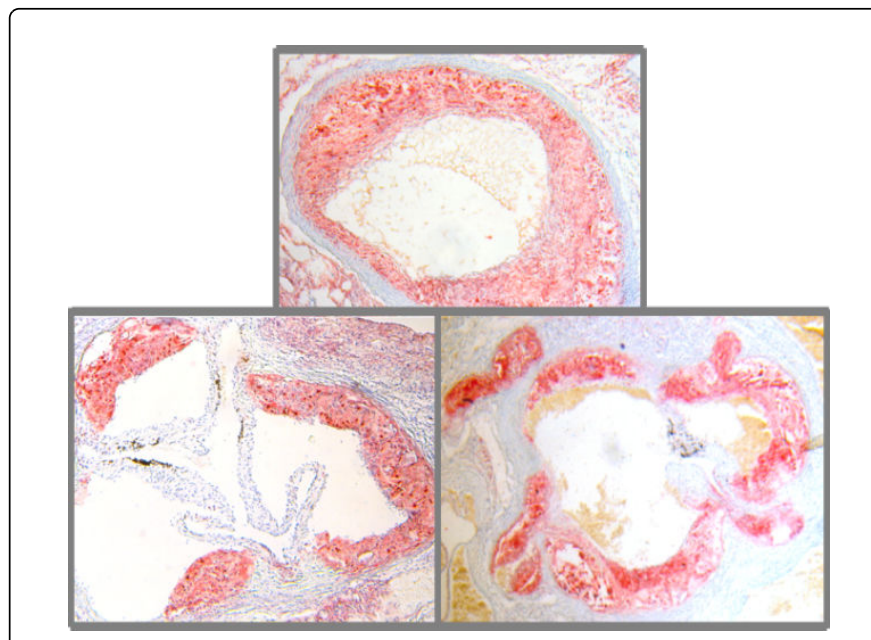

Figure 6: Representative photomicrographs of ascending aorta and aortic roots from a syngraft (Panels A and C) and aortic root of the native heart of an apo E-KO mice. Both aorta and coronary arteries of the syngraft show massive oil red O stating. Such extensive lipidrich lesions were not observed in neither coronary arteries nor ascending aorta in the native heart. Oil red O stain X40.

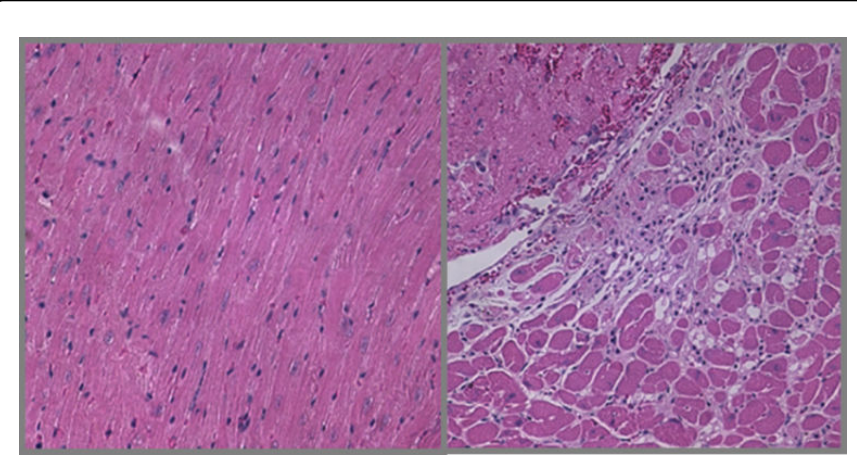

Figure 7: Allograft cardiac transplantation was performed between apo E-KO mice (recipients) and 129J mice (donors). Representative sections from native (Panel A) and allograft (Panel B) mouse myocardium at 6 days post-transplantation. Infiltration of inflammatory cells in the allograft tissue are shown (arrows). Hematoxylin and eosin stain. Panel A X16; Panel B X25.

In conclusion, tissue structure and morphology can be altered by various factors. Extensive alterations in tissue structure and morphology may lead to organ dysfunction. Early detection of such histological/cytological changes will be crucial to implement strategies for correction. We have here reported a number of histological/ cytological alterations in the tissues of apo E-KO mice. Some of these pathological changes could be prevented through dietary approaches, leading to prolongation of organ function. 


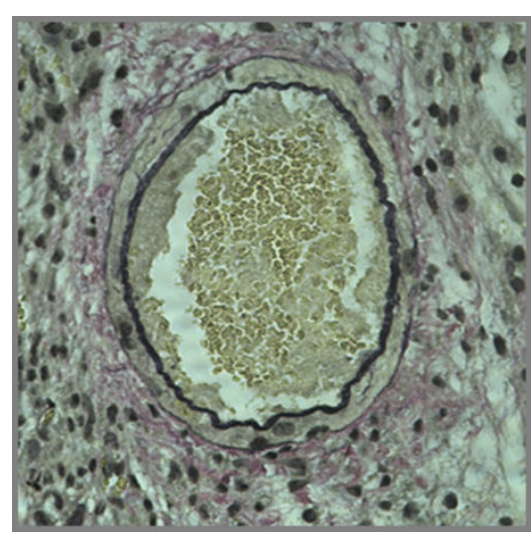

Figure 8: Allograft cardiac transplantation was performed between apo E-KO mice (recipients) and 129J mice (donors). A representative section from an allograft mouse coronary artery at 30 days post-transplantation shows accumulation of inflammatory monocytes in the intima. Verhoeff's stain, X400.

\begin{tabular}{|l|l|l|l|}
\hline $\begin{array}{l}\text { Common } \\
\text { Name }\end{array}$ & Genotype & $\begin{array}{l}\text { Main plasma } \\
\text { lipoprotein particle }\end{array}$ & $\begin{array}{l}\text { Dietary } \\
\text { induced atherogenesis }\end{array}$ \\
\hline C57BL/6 & Wild-type & HDL & Resistant \\
\hline $129 / \mathrm{J}$ & Wild-type & HDL & Resistant \\
\hline Apo E-KO & $\begin{array}{l}\text { Genetically } \\
\text { modified }\end{array}$ & $\beta-V L D L$ & Very sensitive \\
\hline LDL-r-KO & $\begin{array}{l}\text { Genetically } \\
\text { Modified }\end{array}$ & LDL & Sensitive \\
\hline
\end{tabular}

Table 1: Main characteristics of experimental mouse models.

In this regard, Scicchitano et al. [18] have recently reviewed cardiovascular benefits of functional foods and nutraceuticals. Furthermore, Ciccone et al. [19] reported improvements in plasma lipoprotein profile and endothelial function through dietary modifications in overweight patients with diabetes. Such observations, highlight the significant impact of dietary and lifestyle modification in maintain tissue integrity and function.

\section{Acknowledgements}

Dr. Moghadasian's research program is supported by Natural Sciences and Engineering Research Council of Canada (NSERC).

\section{References}

1. Thomas T, Miners S, Love S (2015) Post-mortem assessment of hypoperfusion of cerebral cortex in Alzheimer's disease and vascular dementia. Brain 138: 1059-69.

2. Pulkkinen P, Saarakkala S, Nieminen MT, Jämsä T (2013) Standard radiography: untapped potential in the assessment of osteoporotic fracture risk. Eur Radiol 23: 1375-82.
3. Meier ER, Fasano RM, Estrada M, He J, Luban NL, et al. (2015) Early Reticulocytosis and Anemia Are Associated with Abnormal and Conditional Transcranial Doppler Velocities in Children with Sickle Cell Anemia. J Pediatr 169: 227-231.

4. Mathurin P, Bataller R (2015) Trends in the management and burden of alcoholic liver disease. J Hepatol 62: S38-46.

5. Liao SX, Ding T, Rao XM, Sun DS, Sun PP, et al. (2015) Cigarette smoke affects dendritic cell maturation in the small airways of patients with chronic obstructive pulmonary disease. Mol Med Rep 11: 219-25.

6. Ng YW, Singh M, Sarwal MM (2015) Antibody-mediated rejection in pediatric kidney transplantation: pathophysiology, diagnosis, and management. Drugs 75: 455-72.

7. El Khoury P, Waldmann E, Huby T, Gall J, Couvert P, et al. (2015) Extended-Release Niacin/Laropiprant Improves Overall Efficacy of Postprandial Reverse Cholesterol Transport. Arterioscler Thromb Vasc Biol.

8. Moghadasian MH, McManus BM, Nguyen LB, Shefer S, Nadji M, et al. (2001) Pathophysiology of apolipoprotein E deficiency in mice: relevance to apo E-related disorders in humans. FASEB J 15: 2623-30.

9. Moghadasian MH, Nguyen LB, Shefer S, McManus BM, Frohlich JJ (1999) Histologic, hematologic, and biochemical characteristics of apo Edeficient mice: effects of dietary cholesterol and phytosterols. Lab Invest 79: 355-64.

10. Moghadasian MH, Frohlich JJ (1999) Effects of dietary phytosterols on cholesterol metabolism and atherosclerosis: clinical and experimental evidence. Am J Med 107: 588-94.

11. Solati Z, Moghadasian MH (2015) Use of Animal Models in Plant Sterol and Stanol Research. J AOAC Int 98: 691-6.

12. Moghadasian MH, Frohlich JJ, McManus BM (2001) Advances in experimental dyslipidemia and atherosclerosis. Lab Invest 81: 1173-83.

13. Moghadasian MH, McManus BM, Pritchard PH, Frohlich JJ (1997) "Tall oil"-derived phytosterols reduce atherosclerosis in ApoE-deficient mice. Arterioscler Thromb Vasc Biol 17: 119-26.

14. Moghadasian MH, McManus BM, Godin DV, Rodrigues B, Frohlich JJ (1999) Proatherogenic and antiatherogenic effects of probucol and phytosterols in apolipoprotein E-deficient mice: possible mechanisms of action. Circulation 99: 1733-9.

15. Lai JC, Tranfield EM, Walker DC, Dyck J, Kerjner A, et al. (2003) Heart Stroke Foundation of British Columbia and Yukon, Program Project Grant Investigators. Ultrastructural evidence of early endothelial damage in coronary arteries of rat cardiac allografts. J Heart Lung Transplant 22: 993-1004.

16. Othman RA, Suh M, Fischer G, Azordegan N, Riediger N, et al. (2008) A comparison of the effects of fish oil and flaxseed oil on cardiac allograft chronic rejection in rats. Am J Physiol Heart Circ Physiol 294: H1452-8.

17. Jassal DS, Othman RA, Ahmadie R, Fang T, Zieroth S, et al. (2009) The role of Tissue Doppler imaging in the noninvasive detection of chronic rejection after heterotopic cardiac transplantation in rats. Echocardiography 26: 37-43.

18. Scicchitano P, Cameli M, Maiello M, Modesti PA, Muiesan ML, et al. (2014) On behalf of the "Gruppo di Studio, Ipertensione, Prevenzione e Riabilitazione", Societa Italiana di Cardiologia. Nutraceuticals and dyslipidaemia: Beyond the common therapeutics. J Functional Foods 6: 11-32.

19. Ciccone MM, Scicchitano P, Cortese F, Gesualdo M, Fornarelli F, et al. (2014) Endothelial Function in Obese and Overweight Patients: The Role of Olive Oil, Fish and Nuts. Int J Diabetes Clin Res 1: 1-5. 